\title{
A discussion about some aspects of the solar-terrestrial systems coupling with regard to space weather effects
}

\author{
Clezio M. Denardini ${ }^{1}$, Laysa C. A. Resende ${ }^{1}$, Juliano Moro ${ }^{1}$, Laís M. Guizelli ${ }^{1,2}$ \\ ${ }_{1}$ Aeronomy Division, National Institute for Space Research, S. J. Campos, SP, Brazil \\ ${ }^{2}$ Universidade de Taubaté (UNITAU), Rua Daniel Danelli, s/n Taubaté, SP, Brazil
}

Copyright 2011, SBGf - Sociedade Brasileira de Geofísica

This paper was prepared for presentation during the $12^{\text {th }}$ International Congress of the Brazilian Geophysical Society held in Rio de Janeiro, Brazil, August 15-18, 2011.

Contents of this paper were reviewed by the Technical Committee of the $12^{\text {th }}$ International Congress of the Brazilian Geophysical Society and do not necessarily represent any position of the SBGf, its officers or members. Electronic reproduction or represent any position of the SBGf, its officers or members. Electronic reproduction or storage of any part of this paper for commercial purposes without the written consent
of the Brazilian Geophysical Society is prohibited.

\section{Abstract}

In the present paper we present a discussion about some aspects of the solar-terrestrial system coupling with regard to space weather effects based on some recent studies of energetic particles precipitation at the South American Magnetic Anomaly and the cosmic noise absorption seem by image riometers, and abnormal enhancement of the equatorial sporadic E-layers density during the recovery phase of magnetic storm.

\section{Introduction}

Several studies have been reported in the past and recently dealing with the solar-terrestrial systems interactions due to the solar activity effect and the terrestrial magnetosphere-ionosphere response to these effects. A review with respect to this topic has been published by Prölss (1980). However, he has imitated his review to the ionospheric F-region only. Also, most of the analysis concerned about the ionospheric density only, in what he named ionospheric storm, which essentially is the response of the ionosphere to a geomagnetic storm, which in turn is the response of the Earth magnetosphere (geomagnetic field) to a solar event (CME, solar flare, etc.). Positive ionospheric storm can be defined as an increase in the electron density, compared to the observed electron density during a normal quiet day, while negative ionospheric storm are defined as a decrease in the electron density, compared to the observed electron density during a normal quiet day.

More recently, with the advent of the terminology space weather, these effects are now studied in solar-terrestrial coupling systems point of view. Also, other aspect besides the ionospheric density have been investigated, such as electric fields, gravity waves propagation from below to the E-region heights, 2-day wave in the E-region electric fields (Denardini et al., 2009; Aveiro et al., 2009a; Aveiro et al., 2009b), and also climatological studies to define ionospheric background conditions (Denardini et al., 2005; Shume, 2009) as well as regional peculiarities (Denardini et al., 2003; Denardini et al., 2006). These few studies support our point that there are several events that have to be investigated in a coupled system, and Fig 1 illustrates our point of views of the most obvious sketch showing the interconnection between the solar-terrestrial systems.

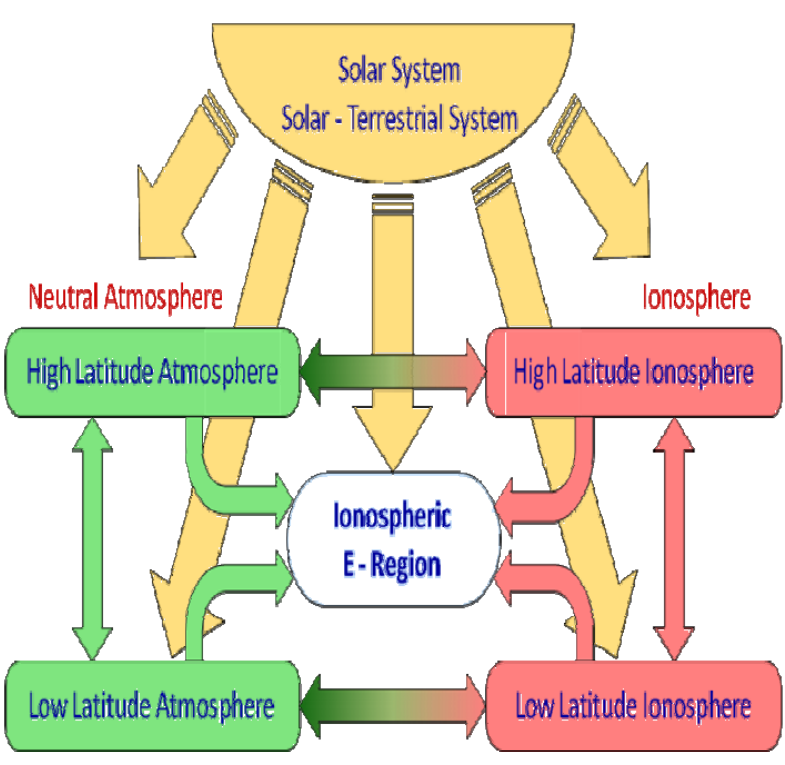

Fig 1. The most obvious sketch showing the interconnection between the solar-terrestrial systems.

This sketch is very comprehensive because it covers most of the connections between the systems, having the ionospheric E-region as a terminator/connecting node. However, in the present paper we intend to investigate two aspects of this connection only. We present a discussion about some aspects of the solar-terrestrial system coupling with regard to space weather effects based on some recent studies of energetic particles precipitation at the South American Magnetic Anomaly (SAMA) and the cosmic noise absorption seem by image riometers, and abnormal enhancement of the equatorial sporadic E-layers density during the recovery phase of magnetic storm.

Studies with respect to the Cosmic Noise Absorption (CNA) has been made since the early 50's, when Mitra and Shain (1953) showed that CNA could be split in two components, one occurring at D-region heights and another occurring at the F-region heights (Abdu, 1966). The last one is often neglected because the critical frequencies of the $\mathrm{F}$ layer (foF2) is 5-10 times the lower than the riometer operational frequency. However, Ramanathan et al. (1961), Abdu et al. (1967) and Kressman (1974) suggested that the CNA at the F-region heights could be as significant as the CNA in others ionospheric regions, when foF2 is higher than $7 \mathrm{MHz}$. Investigations of the latitudinal variation of the relative CNA at the F-region heights to the CNA in others ionospheric regions revealed that this above conclusion is valid for low latitudes only. Indeed, the contribution of the 
F-region to the CNA is proportional to $(f \circ F 2)^{4}$, among other factors (Abdu, 1966). Considering that foF2 has a clear variations with latitude, having a maximum at about $15^{\circ}$ in both North and South magnetic latitudes and decreasing to half of it in latitudes greater than $60^{\circ}$, we assumed that the effects of the F-region in the CNA does not surpassed $1 / 16$, close to our observations site. Also, CNA has no dependence of the density at the D-Regions height. Therefore, it is reasonable to assume that almost all the CNA measure by the riometers installed at the Southern Space Observatory are due to energetic particles precipitation at the D-region height, which is certainly true for the auroral region (Rosenberg et al., 1993). Therefore, in the present paper we show some results of a correlation between the precipitations of energetic particles as measures by the POES satellite and CAN images obtained at the Southern Space Observatory.

With respect of the studies of the presence of Es layers during disturbed periods, it has been already a matter of investigations carried out in a similar study by Batista and Abdu (1977), where they investigate of the presence of Es layers during disturbed periods covering several magnetic storms on the solar cycle 20. They compiled total frequency ( $f t E s$ ) and the blanketing frequency ( $f b E s$ ) and shown well-defined enhancements of the electron density of appreciable magnitude, which were observed 1-3 days after the initiation of the storms. At that time, they had classified the sporadic layers associated with the fbEs enhancements as being type "a" and, after a careful study of winds and recombination rate, they associated the electron density sudden enhancement to particle precipitations from the Van Allen Radiation Belt. However, we see no sporadic layers type "a" in the present study. Due to several characteristics of the trace (height, shape, size, slant, etc.) in the ionograms that we that processed, we classified the sporadic layers that we identified to be associated with the $f b$ Es enhancements as being type "c", instead. This kind of sporadic is associated with wind shears (Wakai et al., 1986). Therefore, we investigated electron density enhancements in terms of the atmosphere dynamics based on magnetic signature of the equatorial electrojet current using magnetometer data. In a more recent study, Afraimovich et al. (2001) established that extreme solar flares may cause sudden changes in the ionospheric ionization, which can lead to global distribution changes. They, shown that enhancements of $X$-ray and UV radiation intensity which are observed during chromospheric flares cause sudden increases in the process of formation of free electrons, increasing the electron density in ionosphere layers. Therefore, we checked for correlation between the occurrence of flares and the associated sporadic $\mathrm{E}$ layer density enhancement obtained from digital sounder at São Luís are studied during the days before, during and subsequent to the December 2003 magnetic storm. Specifically, we studied the abnormal density enhancement in the fbEs that are discusses in terms of the magnetic activity. Furthermore, we aim to show the correlation between occurrence of flares and $E$ layer density enhancement during the magnetic storm, using fbEs as a proxy of foE.

\section{Instrumentation e Methods}

The instrument designed to evaluate the cosmic noise absorption under the SAMA region is the Relative Ionospheric Opacity Meters (RIOMETER), which is essentially a very sensitive radio receivers that have been used to study the CNA since the early 60's (Little and Leinbach, 1959; Lusignan, 1960; Abdu et al., 1967; Abdu et al., 1973; Nishino et al., 1993; Nishino et al., 2002; Nishino et al., 2006). The present one, used in this study, is an Imaging Riometer for Ionospheric Studies (IRIS) installed at the Southern Space Observatory (SSO, $29^{\circ} 4^{\prime}$ S, $53^{\circ} 8^{\prime} \mathrm{W}, 480 \mathrm{~m}$ a.s.I.), São Martinho da SerraBrazil. Its operation is based on determining the Quiet Day Curve (QDC), which methodology has been discussed extensively for several authors (Mitra and Shain, 1953; Lusignan, 1960; Fredriksen and Dyce, 1960; Steiger and Warwick, 1961; Heisler and Hower, 1967; Armstrong et al., 1977; Krishnaswamy et al., 1985; Tanaka et al., 2007).

In order to investigate the abnormal enhancement of the equatorial sporadic E-layers density and its effects in the E-region, we have used a digital ionosonde and two magnetometers. Data from the digital sounders at São Luís (SLZ, $2.3^{\circ} \mathrm{S}, 44.2^{\circ} \mathrm{W}$, dip: -3.3 , an equatorial station, were uses to determine the ionospheric frequency parameters mentioned previously. It has been operated every 15 minutes sending consecutive pulses in the frequencies range from 0.5 to $30 \mathrm{MHz}$, with $0.5 \mathrm{MHz}$ of frequency step. Magnetometers installed at the two sites, SLZ and Vassouras (VSS, $3.9^{\circ} \mathrm{S}, 38.4^{\circ} \mathrm{W}$, dip: -13.3), are used to monitored the Earth's magnetic field at the rate of one measurement per second. However, we have only used the one minute average of the $\mathrm{H}$ component measurements from these two sites so that we could determine the strength of the magnetic effect of the EEJ current at the ground level (named EEJ ground strength for simplification). The basic treatment of the magnetic data at each station is based on to eliminate outlier values from the measured components, based on a $3^{\text {rd }}$ order polynomial fitting. Then, the five quietest days in the month are chosen and their local midnight values averaged $\left(<\mathrm{H}_{0 \mathrm{OLT}}>\right)$. Thereafter, the $\mathrm{H}$ component variations are normalized to the difference between the $\mathrm{H}$ component values and the mean midnight values for the five quietest days providing the $\Delta \mathrm{H}$, i.e., $\Delta \mathrm{H}_{S L Z}=\mathrm{H}_{S L z}-$ $<H_{00 L T @ S L z}>$. Finally, the diurnal variation of the EEJ ground strength is estimated by taking the difference between the $\Delta \mathrm{H}$ values at a station at the dip equator $\left(\Delta \mathrm{H}_{\mathrm{SLZ}}\right)$ and that at a station nearby the dip equator but outside the EEJ influence ( $\left.\Delta \mathrm{H}_{\mathrm{VsS}}\right)$. A more detailed explanation on the magnetic data treatment and on the use two stations is explained by Denardini et al. (2009).

\section{Results}

With regard to the space weather effects related to CNA observed within IRIS, Nishino et al. (2002) have observed a CNA event on during the main phase of the intense geomagnetic storm occurred on 22 and 23 September 1999 (Dst $=-164 \mathrm{nT})$ by the IRIS $(38.2 \mathrm{MHz})$ at the SSO, Southern of Brazil. We have reprocessed the same data set and we found the special distribution and temporal evolution of the event as presented in the Fig. 2. Each 
image is obtained at $\sim 2$ min interval and represents a $300 \times 300 \mathrm{~km}$ horizontal area in the IRIS field of view at about $100 \mathrm{~km}$ of altitude.
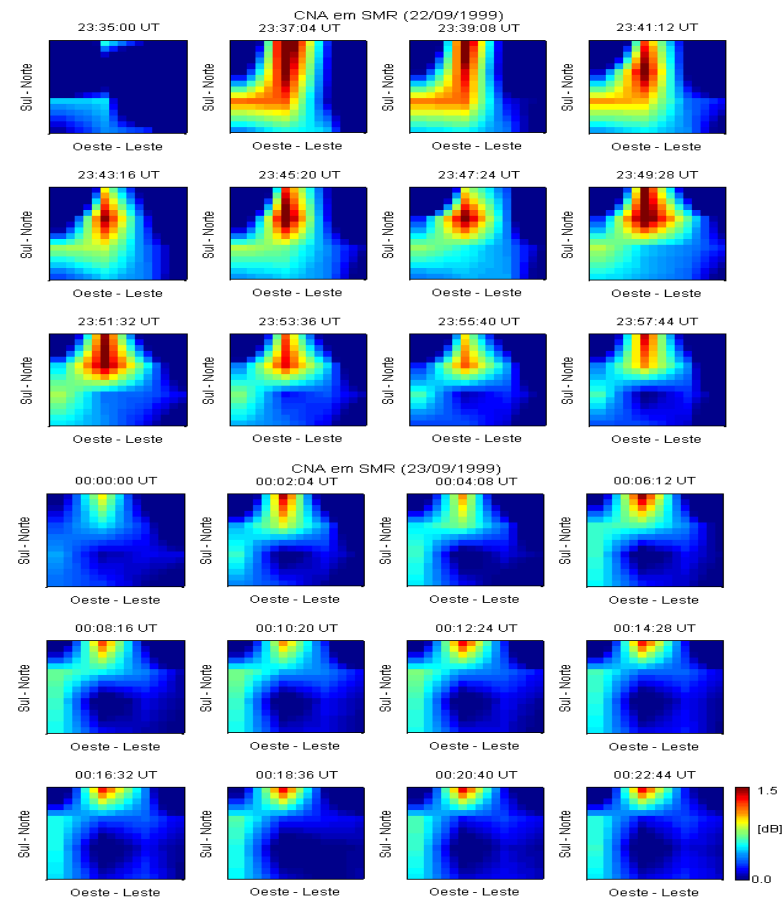

Fig 2. Images of the Cosmic Noise Absorption Images obtained during the main phase of the geomagnetic storm occurred on 22 and 23 September 1999 by the IRIS (38.2 MHz) at the SSO. The color scale gives the intensity of the CNA in $d B$.

Fig. 2 clearly shows a quite weak area of absorption appearing at southwestern region of the first image suddenly that becomes a strong area connecting the western field of view of the IRIS with the Northern area that means low latitudes. Differential analysis of the images evolution revealed that this northward elongated structure is migrating eastward with a drift velocity of about $250 \mathrm{~m} / \mathrm{s}$. Also, it is getting weaker as the main phase of the magnetic storm evolves.

Ionospheric data (not shown here) were acquired for the same period at the closest digisonde available, i.e., at Cachoeira Paulista (SP), which is $\sim 1000 \mathrm{~km}$ far away the SSO. No abortion effects were observed there. Therefore, despite we have no reason to confirm that this CNA event observed in the IRIS data at the SSO is due to particles precipitation, we cannot discard this possibility of as well. If we assume a background electric field of about 1.8 $\mathrm{mV} / \mathrm{m}$, we will find that electrons precipitating in the Southern American Magnetic Anomaly (SAMA) must have energy around $20 \mathrm{keV}$. Such intensity of the electric field is quite reasonable for the E-region height if we consider Disturbance Dynamo Electric Fields associated with a magnetic storm of sub-storms.

Therefore, we integrated all the CNA inside each frame and correlated with measurement of energetic particles made by the MEPED detector, on board of the POES satellite. An example of a Contour map of electron flux within the energy range of lower $30 \mathrm{keV}$ derived from the POES satellite at $840 \mathrm{~km}$ of altitude is shown in the Fig. 3 .

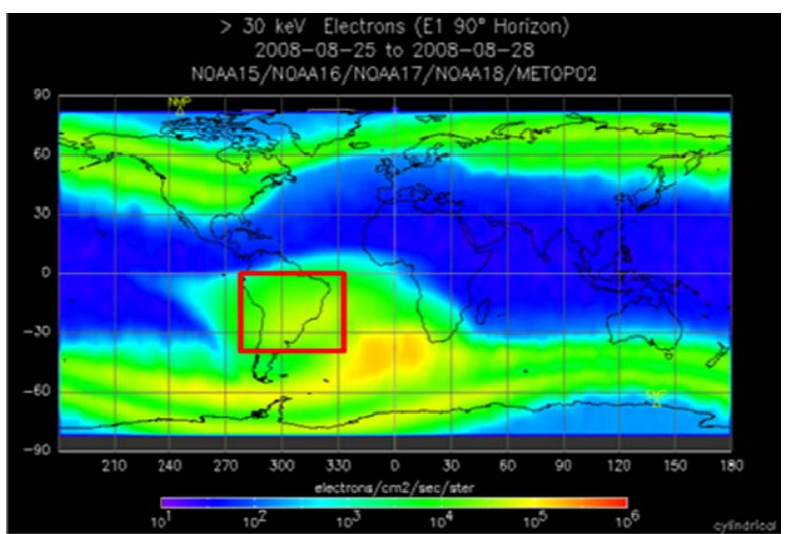

Fig 3. Contour map of electron flux within the energy range of lower $30 \mathrm{keV}$ derived from the POES satellite at $840 \mathrm{~km}$ of altitude. AFTER: SWPC (2001).

In our analysis we considered only those particles measure in the region of the satellite orbit corresponding to the projection of the field of view overhead the IRIS. Both MEPED detectors (the one aligned to the zenith and the one aligned with the horizontal satellite path) were considered in the analysis. All the measurement of the different particles (electrons and protons) within all measured energy ranges were taken in to account. The best fit (95\%) was found between electron flux distribution within the energy range of between 30 and $300 \mathrm{keV}$ and the four-day running averaged max CNA values detected by the imaging riometer installed at the SSO (Fig. 4). Therefore, we attribute the occurrence of this CNA event to particle precipitation in SAMA region.

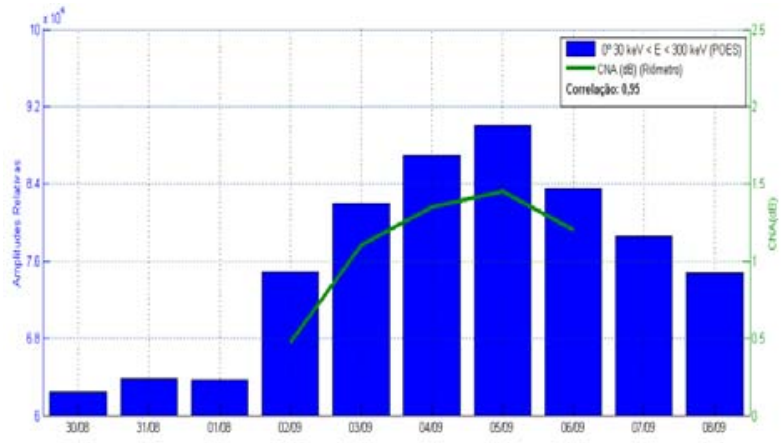

Fig 4. Histogram of electron flux distribution within the energy range of between 30 and $300 \mathrm{keV}$ detected over the SAMA region derived from the POES satellite at $840 \mathrm{~km}$ of altitude (blues bars) and the four-day running averaged max CNA values detected by the imaging riometer installed at the SSO (green line).

With respect to space weather effects related associated with abnormal enhancements of the equatorial sporadic E-layers density during the recovery phase of magnetic storm, we show the variation of the fbEs (green line) and $\mathrm{ftEs}$ (brown line) at SLZ on the middle panel of Fig. 5. On the top panel of the same figure is shown the variation of the Dst index, and the variation of the X-ray solar radiation intensity measured in the range 0.5-4.0 Angstrom (red line) and 1.0-8.0 Angstrom (blue line) from 
October 26 to November 3, 2003. All the data are referred in UT. The Dst intensity variation is given in nT and its linear scale is shown in the left vertical axis of the top panel. Both $f b E s$ and $f b E s$ are given in $\mathrm{MHz}$ and their linear scale is shown in the left vertical axis of the middle panel. The X-ray solar radiation intensity in both bands is given in $\mathrm{W} / \mathrm{m}^{2}$ and their logarithmic scale is shown in the left vertical axis of the bottom panel. On the right vertical axis of the bottom panel it is also shown a classification of the flare according to the intensity reached by the peak of the X-ray flux Somov and Syrovatskii (1972).

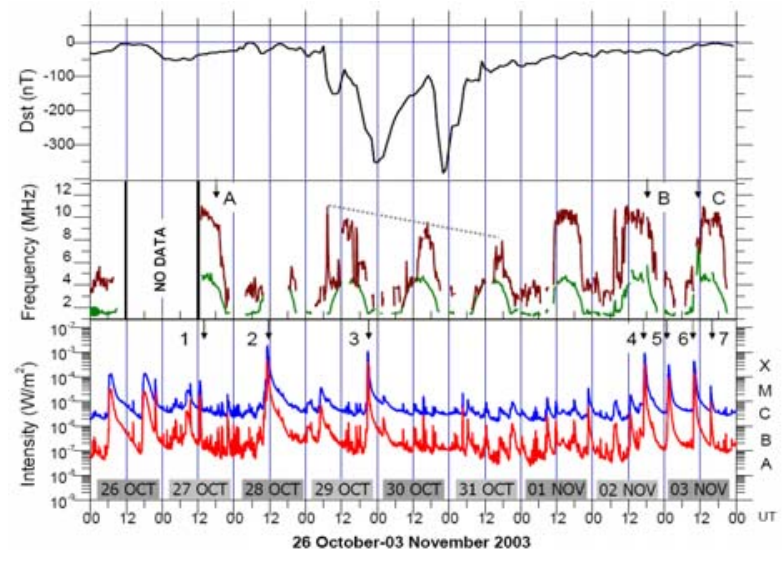

Fig 5. Variation of the Dst index on the top, the variation of the fbEs (green line) and ftEs (brown line) at São Luís on the middle panel, and the variation of the $X$-ray solar radiation intensity measured in the range 0.5-4.0 Angstrom (red line) and 1.0-8.0 Angstrom (blue line) from October 26 to November 3.

During the magnetic super storm occurred on October 2003 , the behavior of these frequency parameters was altered in an attention-grabbing way. The digisonde registered sequentially smaller values for the $\mathrm{ftEs}$ maximum daily peak from October 29 to 31 (identified by the dotted line in the middle panel of the Fig. 5. Also, an anomalous intensification of the ionospheric density (determined from the $f b E s$ ) that exceeded the normal ambient background values for local time and location could be seen some days after the main phase of the storm (identified in the middle panel of the figure Fig. 5 by the arrow labeled with the letter $B$ and $C$ ).

The sequentially smaller values of the ftEs maximum daily peak started on the initial phase of the magnetic storm and lasted until the beginning of the recovery phase. On October 29, ftEs maximum daily peak reached $\sim 10 \mathrm{MHz}$ around midday, it decreased to $9.5 \mathrm{MHz}$ on October 30 and decreased to $8 \mathrm{MHz}$ on October 31. Afterwards, the value of the $\mathrm{ftEs}$ maximum daily peak returned to the typical level of $11 \mathrm{MHz}$ (normally found around local midday). Despite being a remarkable characteristic of the frequency parameters measured during this event, we were not able to collect enough evidences to provide a definitive explanation for the declination in the $\mathrm{ftEs}$ maximum daily peak measured during the main phase of the super storm. Nevertheless, from the magnetic measurement of the EEJ ground strength (presented in the Fig. 6) we identified that during the period when the declination in the $\mathrm{ftEs}$ maximum daily peak was measured the EEJ current was very weak, meaning weak EEJ polarization electric field. Thereafter, we suggest that a electromagnetic rearrangement on the $\mathrm{Sq}$ system, i.e., Disturbance Dynamo effects could be ruling over the equatorial environment at the E-region heights during that period. This is supported by the fact that the ftEs is a parameter taken from the $\mathrm{ES}_{\mathrm{q}}$ layer, which is associated to EEJ plasma instabilities, which are in turn driven by the EEJ electric field that we state to be weak during that period.

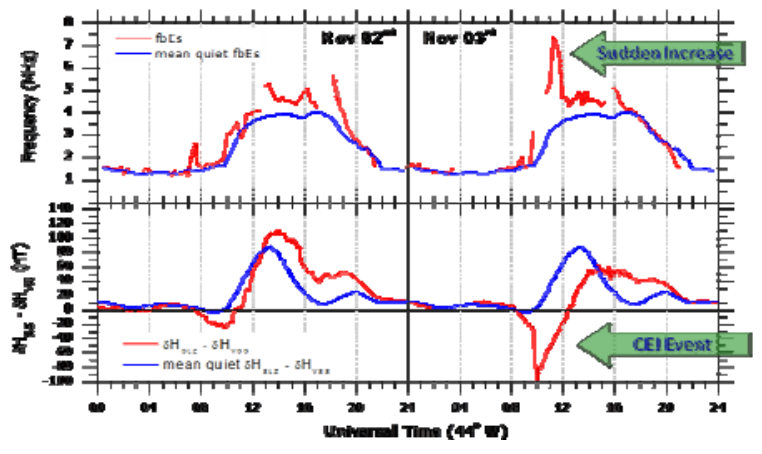

Fig 6. Diurnal variation of fbEs and the effect of the chain of the induced equatorial electrojet in the ground in days 02 and 03 of November. The blue line shows the average secular variation of the same parameters above for the calm period of 10 the 12 of October.

With respect to the anomalous intensification of the ionospheric density, it was determined from sudden peaks in the fbEs (used as a proxy of the foE), two main interpretation rise from these impressive increases in the electron density, especially those that were identified during the recovery phase of the October 2003 super storm. The first one deals with radio signal absorption (in the HF band) commonly known to happen in the D-region. The second interpretation is thought in term of the dominant process that is ruling the Es formation at the time of the sudden intensification. Whichever was the explanation, the present result still is a evidence of the reaction of the ionospheric-termospheric system to space weather forcing.

Supporting the first hypothesis, we know that an extra amount of X-ray or EUV solar radiation could have increased the D-region density leading to an increase of its opacity for lower wavelength electromagnetic signal propagating upward (Abdu, 1966; Abdu et al., 1967; Abdu et al., 1973). In this case, the lower frequencies of the digisonde would be blocked and the $f b E s$ no longer can be used as a proxy of the foE. Therefore, the results we are interpreting as electron density increases at the Eregion height are indeed a response of the D-region density to sudden X-ray and/or EUV solar radiation. Supporting the second hypothesis, we mentioned that we observed a suddenly appearance of the type "c" sporadic layer (Es-c) that replaced the normally observed sporadic layers of the type "q" $\left(E s_{q}\right)$. Also, we know that the different types of sporadic layer are classified according to the different mechanisms of formation and location that they are observed. Moreover, the $\mathrm{Es}_{\mathrm{c}}$ is an E-region ionization enhancements that is associated with vertical shear caused by apposite horizontal neutral winds at the 
E-region height normally identifies in middle latitudes (Whitehead, 1989).

In order to check the most plausible explanation, we verified the evolution of the type of Es layer during the event occurred on November 3 (not shown here). Also, we consider the influence on the $\mathrm{X}$-ray radiation due to burst solar events by investigating increases in the of the $X$-ray radiation in ranges $0.5-4.0$ and 1.0-8.0 Angstrom using measurement by XRS at the GOES 10 (arrow 1 to 7 in lower panel of figure Fig. 5). However, we no longer have a definitive answer. Therefore, we will keep these two possibilities as probable explanations for the observed abnormal electron density enhancement of the equatorial sporadic E-layers density during the recovery phase of magnetic storm.

\section{Conclusions}

We identified two kind of event associated with space weather that were measured during magnetic storms in the Brazilian sector, both at low latitudes. We observed a CNA event on during the main phase of the intense geomagnetic storm occurred on 22 and 23 September 1999 (Dst $=-164 \mathrm{nT})$ by the IRIS $(38.2 \mathrm{MHz})$ at the SSO, Southern of Brazil, drifting eastward with at about $250 \mathrm{~m} / \mathrm{s}$ and getting weaker as the main phase of the magnetic storm evolves. Calculated the energy of the probable precipitating particles and checking within the MEPED detector on board of the POES satellite, we attribute the occurrence of this CNA event to particle precipitation in SAMA region. We also were able to identify a sequence of smaller values for the $f t E s$ maximum daily peak from October 29 to 31, explained as an effect of the Disturbance Dynamo in response to the energy injection dues to the super magnetic storm. Also, an anomalous intensification of the ionospheric density (determined from the fbEs) that exceeded the normal ambient background values for local time and location could be seen some days after the main phase of the storm. Two possible explanations were raised for this event. The first one deals with the radio signal absorption (commonly known to happen in the D-region, while the second points out that the changes of the types of sporadic layer, which leads to different mechanisms of formation.

\section{Acknowledgments}

C. M. Denardini thanks to CNPq/MCT for the Grants 305923/2008-0 and 470553/2009-0 that partially supported the present study. He also thanks to FAPESP for supporting the national travel (Grant 2011/10173-4) to attend the CISBGf meeting. L. C. A. Resende thanks to Capes/MEC for her MSc. fellowship. J. M. thanks to CNPq/MCT for supporting his master program (Grant 130497/2009-6). Authors thank to NOAA for the GOES and POES satellites data availability.

\section{References}

Abdu, M. A., Degaonkar, S. S., Ramanathan, K. R., Attenuation of galactic radio noise at $25 \mathrm{MHz}$ and $21.3 \mathrm{MHz}$ in the ionosphere over Ahmedabad during 1957-1964. Journal of Geophysical Research, v. 72, p. 1547-1554, 1967.

Abdu, M. A., Ananthakrishnan, S., Coutinho, E. F., Krishnan, B. A., Reis, E. M. da S., Azimuthal drift and precipitation of electrons into the South Atlantic Geomagnetic Anomaly during an SC Magnetic storm. Journal of Geophysical Research, v. 78, p. 5830-5836, 1973.
Abdu, M. A. Galactic radio noise attenuation in the ionosphere. 147 p. Ph.D. Thesis - The Gujarat University, Ahmedabad, India, 1966.

Afraimovich, E. L., Altyntsev, A. T., Kosogorov, E. A., Larina, N. S., Leonovich, L. A., Ionospheric effects of the solar flares of September 23, 1998 and July 29, 1999 as deduced from global GPS network data. J. Atmos. Solar-Terr. Phys., v63, 1841-1849, 2001.

Armstrong, R. J., Berkey, F. T., Melbye, T. The day to night absorption ratio in auroral zone riometer measurements. Planet Space Science, 25, 1193-1198, 1977.

Aveiro, H.C., C.M. Denardini, and M.A. Abdu, Climatology of gravity waves-induced electric fields in the equatorial $\mathrm{E}$ region, Journal of Geophysical Research, 114 (A11308), doi:10.1029/2009JA014177, 2009a.

Aveiro, H.C., C.M. Denardini, and M.A. Abdu, Signatures of 2 day wave in the E-region electric fields and their relationship to winds and ionospheric currents, Annales Geophysicae, 27 (2), 631-638, 2009b.

Batista, I. S., Abdu, M. A., 1977. Magnetic storm delayed sporadic $E$ enhancements in the Brazilian geomagnetic anomaly, J. Geophys. Res, 82(29), 4777-4783.

Denardini, C.M., M.A. Abdu, and J.H.A. Sobral, Detection of three distinct regions in the equatorial electrojet in the Brazilian sector, Brazilian Journal of Geophysics, 21 (1), 6574, 2003.

Denardini, C.M., M.A. Abdu, E.R. de Paula, C.M. Wrasse, and J.H.A. Sobral, VHF radar observations of the dip equatorial E-region during sunset in the Brazilian sector, Annales Geophysicae-Atmospheres Hydrospheres and Space Sciences, 24 (6), 1617-1623, 2006.

Denardini, C.M., M.A. Abdu, E.R. de Paula, J.H.A. Sobral, and C.M. Wrasse, Seasonal characterization of the equatorial electrojet height rise over Brazil as observed by the RESCO $50 \mathrm{MHz}$ back-scatter radar, Journal of Atmospheric and Solar-Terrestrial Physics, 67 (17-18), 1665-1673, 2005.

Denardini, C.M., M.A. Abdu, H.C. Aveiro, L.C.A. Resende, P.D.S.C. Almeida, E.P.A. Olivio, J.H.A. Sobral, and C.M. Wrasse, Counter electrojet features in the Brazilian sector: simultaneous observation by radar, digital sounder and magnetometers, Annales Geophysicae, 27 (4), 1593-1603, 2009.

Fredriksen, A.; Dyce, R. B. Ionospheric absorption investigations at Hawaii and Johnston Island. Journal of Geophysical Research, v. 65, 1177-1181, 1960.

Heisler, R., Hower, G. L., Riometer quiet day curves. Journal of Geophysical Research, v. 72, 5485-5490, 1967.

Kressman, R. I. Riometer studies at South Georgia. 1974.

Krishnaswamy, S.; Detrick, D. L.; Rosenberg, T. The inflection point method of determining riometer quiet day curves. Radio Science, v. 20, n. 20, 123-136, 1985

Little, C.G., Leinbach, H.; The riometer-a device for continuous measurements of ionospheric absorption. Proceedings of the IRE 46, 320-325. 1959.

Lusignan, B. Cosmic noise absorption measurements at Stanford, California, and Pullman, Washington. Journal of Geophysical Research, v. 65, 3895-3902, 1960.

Mitra, A. P.; Shain, C. A. The measurement of ionospheric absorption using observation of $18.3 \mathrm{mc} / \mathrm{s}$ cosmic radio noise. Journal of Atmospheric and Terrestrial Physics, v. 4, 204-218, 1953. 
Nishino, M., Tanaka, Y., Oguti, T., Yamagishi, H., Holtet, J. A., Initial observations results with imager riometer at NY-Alesud $(L=16)$. NIPR Symp. Upper Atmosphere Physics, v. 6, p. 47-61, 1993.

Nishino, M., Makita, K., Yumoto, K., Rodrigues, F. S., Schuch,N. J., Abdu, M. A. Unusual ionospheric absorption characterizing energetic electron precipitation into the South Atlantic Magnetic Anomaly. Earth,Planets, and Space, v. 54, p. 907-916, set. 2002.

Nishino, M., Makita, K., Yumoto, K., Miyoshi, Y., Schuch, N. J., Abdu, M. A. Energetic particle precipitation in the brazilian geomagnetic anomaly during the "Bastille Day Storm" of July 2000. Earth, Planets, and Space, v. 58, p. 607-616, maio 2006.

Ramanathan, K. R.; Bhonsle, R. V.; Degaonkar, D. D. Effect of electron-ion collisions in the $\mathrm{F}$ region of the ionosphere on the absorption of cosmic radio noise at $25 \mathrm{Mc} / \mathrm{s}$ at Ahmedabad: Changes in absorption associated with magnetic storms. Journal of Geophysical Research, v. 66, p. 2763-2771, set. 1961.

Rosenberg, T. J.; Wang, Z.; Rodger, A. S.; Dudeney, J. R.; Baker, K. B. Imaging riometer and HF radar measurements of drifting $F$ region electron density structures in the polar cap. Journal of Geophysical Research, v. 98, p. 7757-7764, may 1993.

Shume, E. B., C. M. Denardini, E. R. de Paula, and N. B. Trivedi, Variabilities of the equatorial electrojet in Brazil and Peru, Journal of Geophysical Research doi10.10292009JA014984 in press 2009.

Somov, B.V and Syrovatskii, S.I.1972. Magnetically driven motions in solar corona, Soviet Phys. 34, 332-335.

Steiger, W. R.; Warwick, J. W. Observations of cosmic radio noise at $18 \mathrm{mc} / \mathrm{s}$ in Hawaii. Journal Of Geophysical Research, v. 66, p. 57\{66, jan. 1961.

SWPC. The NOAA POES (TIROS) Medium Energy Proton and Electron Detector. 325 Broadway, Boulder CO 80305, USA: NOAA Space Weather Prediction Center, 2001. Avaliable: <http://www.swpc.noaa.gov/pmap/PoesSem.html>. Access on: 04 November 2010.

Tanaka, Y., Makita, K., Nishino, M., Ookawa, T., Development of data analysis program for imaging riometer by using MATLAB. Bulletin of science and engineering, Takushoku University, Takushoku University, v. 10, n. 1, p. 61, 2007.

Wakai, N., H. Ohyama, and T. Koizumi, Manual of Ionogram Scaling. Revised Edition, pp. 120, Radio Research Laboratory, Tokyo, 1986.

Whitehead, J.D., 1989. Recent Work on Mid-Latitude and Equatorial Sporadic-E, J. Atmos. Solar-Terr. Phys., 51 (5), 401-424. 